\title{
Frege on Sense-Identity, Basic Law V, and Analysis
}

\author{
Philip A. Ebert
}

Penultimate Draft

\section{Introduction: An incompatible triad}

Frege's Logicism has been subject to a variety of different interpretations. The following three thesis have individually been associated with key aspects of Frege's philosophy, yet they are jointly incompatible:

Informativeness Arithmetical identity statements are informative because the senses of the expressions flanking the identity sign are distinct.

Analysis Arithmetical identity statements are analysable into logical identity statements by providing (term by term) sense-preserving analyses.

Logical Identity Logical identity statements are logically true in virtue of an identity of senses of the expressions flanking the identity.

The three claims constitute an incompatible triad: [Informativeness] requires that the expressions flanking an informative arithmetical identity are distinct. According to [Analysis], there is a corresponding logical identity which properly captures the senses of the original arithmetical expressions. Yet, given [Logical Identity], the relevant logical identity will be such that the two sides flanking the identity sign express the same sense. Something, it seems, has to go. ${ }^{1}$

Given that there is little doubt amongst Frege scholars that Frege was indeed committed to [Informativeness], the two natural avenues to resolve the

\footnotetext{
${ }^{1}$ The presentation draws on (Milne, 1989) which inspired much of the discussion. Milne does not explicitly state [Analysis] in his discussion but he seems to suggest that Frege is subject to this kind of incompatibility. Milne mentions (Currie, 1982) for bringing the issue to his attention while crediting (Thiel, 1968) for first raising a similar puzzle.
} 
triad are to argue against [Analysis] or against [Logical Identity]. ${ }^{2}$ With the exception of the last section, where I briefly discuss a rejection of [Analysis], I will here mainly focus on [Logical Identity]. The main theme of this paper can be motivated as follows:

If we accept [Logical Identity], we have to interpret Frege - at least before the discovery of the paradox - as holding the view that the constituent clauses flanking the main identity of his infamous basic law $\mathrm{V}$ :

$$
\vdash(\dot{\varepsilon} f(\varepsilon)=\dot{\alpha} g(\alpha))=(\mathfrak{a}-f(\mathfrak{a})=g(\mathfrak{a}))^{3}
$$

express the same sense. For simplicity, I will label this more specific claim:

BLV Synonymy Constituent clauses flanking the main identity of basic law $\mathrm{V}$ express the same sense.

Proponents of [BLV Synonymy] provide additional support by drawing on the more general thesis which Frege purportedly held:

Abstraction Synonymy Constituent clauses of an abstraction principle express the same sense.

Support for this interpretation is sometimes drawn from the observation that in Grundlagen Frege seems to regard the constituent clauses of the direction abstraction principle or of Hume's Principle 4 as expressing the same content. ${ }^{5}$ The main aim in the next two sections is to challenge [Abstraction Synonymy] and [BLV Synonymy] more specifically as adequate interpretations of Frege's philosophy. If successful, we can then assess the prospects of rejecting [Logical Identity] to avoid the incompatible triad.

\footnotetext{
${ }^{2}$ [Analysis] is suggested by numerous passages in Frege, compare the discussion in (Blanchette, 2012), p.79-82. [Logical Identity] is defended most prominently in (Sluga, 1986), p.60 and see also (Sluga, 1980), p.156.

${ }^{3}$ In words: The value range of the function $\Phi(\xi)$ is identical to the value range of the function $\Psi(\xi)$ if and only if the function $\Phi(\xi)$ and the function $\Psi(\xi)$ always have the same value for the same argument (i.e. they are co-extensional). BLV has the form of an abstraction principle:

$$
M(f)=M(g) \leftrightarrow f \approx g
$$

where $M$ is a term-forming operator applicable to expression of the type of $f$ and $g$ and $\approx$ is an equivalence relation on entities denoted by expressions of that type.

${ }^{4}$ Direction Abstraction is an abstraction principle that fixes the identity conditions of directions by appeal to parallelism of lines (to be discussed below). Hume's Principle, a principle that is defended by the Neo-Fregeans in their reconstruction of logicism, fixes the identity conditions of cardinal numbers by appeal to equinumerosity as the relevant equivalence relation. Compare (Wright, 1983) and (Hale and Wright, 2001).

${ }^{5} \mathrm{I}$ will focus here only on the relevant content/sense identity claim with respect to the constituent clauses of an abstraction principles. Cf. (Picardi, 1993), p.76. Of course, how best to understand the notion of content in Grundlagen will be discussed in more detail below. Part of the difficulties in interpreting this notion arises from unresolved
} 


\section{Abstraction Synonymy: Grundlagen}

Let us distinguish four different phases in Frege's development that relate to [Abstraction Synonymy]. Accordingly, there is the early period, which includes the publication of Begriffsschrift in 1879, the middle period, which covers the period from the publication of Grundlagen der Arithmetik in 1884, up to but excluding the publication of "Function und Begriff" in 1891. Then there is what may be called the mature period: the period that begins with the introduction of his famous sense-reference distinction in "Function und Begriff" and which includes his magnum opus Grundgesetze der Arithmetik published in two volumes in 1893 and 1903; Frege's late period, then, comprises his main writings after he abandoned his theory of value-ranges (it is admittedly difficult to date the start of the late period).

Most Frege scholars maintain that Frege adopted [Abstraction Synonymy] during his middle period with respect to the notion of content. To name but a few: Beaney, Blanchette, Burge, Currie, Dummett, Milne, Picardi, Sluga, Sullivan, and Weiner. ${ }^{6}$ Some interpreters argue that Frege did not adopt [Abstraction Synonymy] after introducing the sense-reference distinction, and that he did reject [BLV Synonymy] in Grundgesetze. Most notably here are Dummett, Klement and Landini. ${ }^{7}$ Others such as Beaney, Burge, Curry, Milne, and Sluga argue that Frege was committed to [Abstraction Synonymy] and [BLV Synonymy] during the mature period, in particular in his Grundgesetze. In the following, I will first look at numerous passages in Grundlagen to investigate whether Frege did entertain [Abstraction Synonymy] during his middle period and then proceed to investigate the relevant writings of his mature period. With the exception of one passage, I will leave aside a detailed discussion of Begriffsschrift, i.e. his early period, since what is most relevant for my discussion is Frege's attitude towards sameness of content/sense of the relevant sides of an abstraction principles - this issue first arises in Grundlagen. Also, I will not discuss in detail Frege's views post Rus-

question of how to interpret Frege's notions of (judgeable/conceptual) content and identity in Begriffsschrift and to what extend these views transfer to Grundlagen. For example, on one interpretation, "sameness of judgeable content" is fairly weak and merely requires provable equivalence. As I will argue below, Frege adopted a stronger notion of sameness of content in Grundlagen.

${ }^{6}$ Compare: (Beaney, 1996), (Beaney, 2005), (Blanchette, 2012), (Burge, 1990), (Currie, 1982), (Dummett, 1981) (Dummett, 1991b), (Dummett, 1991c), (Milne, 1989), (Milne, 2014), (Picardi, 2012), (Sluga, 1986), (Sluga, 1986), (Sullivan, 2007), and Weiner (personal correspondence).

${ }^{7}$ (Dummett, 1991c), chapter 14, (Klement, 2002), and (Landini, 1996) who also maintains that provided identity of content requires more than provable equivalence, Frege never adopted [Abstraction Synonymy] in any period. 
sell's paradox - most notably his famous article "Logik in der Mathematik" written around 1914. This paper requires separate treatment and since, as I think is most likely, Frege had given up on his theory of value-ranges by 1914, I'm not confident that the claims made in "Logik in der Mathematik" about logic are a reliable guide to interpret Frege's attitude towards basic law $\mathrm{V}$ during the mature period. ${ }^{8}$

Let us first discuss the famous passage of Grundlagen which is regarded as the "birth-place" of [Abstraction Synonymy]. In this passage, Frege does not consider BLV but he discusses the direction abstraction principle which introduces the concept direction by means of the equivalence relation parallelism. Given, however, that Frege claims that similar considerations apply to other abstraction principles, scholars draw on this passage in support of [Abstraction Synonymy] more generally. ${ }^{9}$ It is worth quoting the passage in full: ${ }^{10}$

"The judgement: "the line a is parallel to the line b" [A1], in signs:

$$
\mathrm{a} / / \mathrm{b}
$$

can be regarded as an equation. When we do this, we obtain the concept of direction and say: "the direction of line a is equal to the direction of line b" [A2]. | Thus, we replace the sign // by the more general $=$, by distributing (vertheilen) the specific content of the former between $\mathrm{a}$ and $\mathrm{b}$. We split up the content in a way different from the original and gain thereby a new concept. Often, of course, one conceives of the matter the other way round, and some teachers define: parallel lines are those whose directions are equal. [...] Too bad, however, that thereby the true order

\footnotetext{
${ }^{8}$ This cautionary remark requires further research. Nonetheless, the following is worth noting: assuming that the discovery of the inconsistency not merely had major formal consequences for Frege's logicism but likely affected Frege's philosophy as a whole, in particular his epistemology of logic, Frege's views on logic and its epistemology might well have changed significantly sometime after he came to realise that his revised basic law $\mathrm{V}^{\prime}$ is not fit for the logicist task (likely sometime after 1906)-indeed he later gave up on logicism altogether. Hence, I think that one should treat with much caution quotations from his later period with regards to an epistemology of logic that are then used to support an interpretation of Frege's views about logic, in particular about basic law V, during the middle or mature period.

${ }^{9} \mathrm{He}$ writes in a footnote to $\S 65$ "The essentials of this discussion can easily be transferred to the case of number-equality" - that is the abstraction principle known as Hume's Principle. Thus, there is reason to think that these considerations apply to other abstraction principle as well.

${ }^{10}$ All translations of Frege's original are by the author, apart from the quoted passages of Grundgesetze which are based on (Frege, 2013).
} 
of things is reversed. For surely everything geometrical must originally be given in intuition. Now, I may ask if anyone has an intuition of the direction of a line? Of a line, certainly, but does one further distinguish in one's intuition this line from its direction? Hardly so! This concept of direction is only to be discovered by means of an intellectual activity which starts from an intuition."

(Frege, 1884), p.74-5.

Most scholars interpret Frege as suggesting that the idea of splitting up content $^{11}$ results in [A1] and [A2] having the same content. However, Frege does not explicitly say that the right- and left-hand side of the direction abstraction have the same content. What he does say is this:

"Thus, we replace the sign // by the more general =, by distributing the specific content of the former between a and b. We split up the content in a way different from the original and gain thereby a new concept."

Frege does not claim that the resulting content of the whole clause [A2] is exactly the same as that of the clause [A1]. In fact, in the first sentence, he does not even mention the content of the whole constituent clause [A1], but he focuses on the content of the sign "//". The second sentence of the quotation then picks up on "the" content. Admittedly, the original here is ambiguous and it can be "the" content of the sign "//" or "the" content of [A1] that Frege is referring to. Whatever it is, although the definite article suggest that there is one content (i.e. of the sign or of [A1]), he does not say explicitly that the resulting content of [A2] has to be the same. Frege's main emphasis in this passage is something very different. He is concerned with the process of concept-formation: that, by splitting up a specific content, we can constitute, and grasp for the first time, a new concept - in the given case, the concept of direction. Whether there is sameness of content of the relevant sentences is not the main issue; instead, by drawing attention to the form of an abstraction principle, he presents us with an effective means for introducing a new concept. ${ }^{12}$ This method, of course, does not require

\footnotetext{
${ }^{11}$ Frege uses "zerspalten" which is rendered using "split up" - a choice of translation also shared by Dummett in (Dummett, 1991c), p.168. Austin uses "carve up" in his translation which is appropriate but often used by others in a possibly misleading manner: interpreters have used "to recarve" or indeed the phrase "recarving of content", which suggests that the content remains the same - a claim I'm about to challenge.

${ }^{12}$ That this means of forming new concepts does not suffice as a definition proper is shown in the ensuing passages of Grundlagen. The feature of concept-constitution of an
} 
the content of the new concept in [A2] to be identical to some concept that figures in [A1], however, it does not seem to require either that the two sides [A1] and [A2] have the same content - there is, after all, a creative element in the method of splitting up content. ${ }^{13}$ So, in contrast to most interpreters, I believe that $\S 64$ alone does not provide enough support for [Abstraction Synonymy]. ${ }^{14}$

In fact, the remainder of $\S 64$ seems to raise a serious challenge for the proponent of [Abstraction Synonymy]. Having presented the idea of splitting up content, Frege maintains that [A2] cannot be used to define the content of [A1] because the latter only is rooted "in intuition". So we might wonder: if he really thought that both propositions express the very same content, what is it then about [A1] - if not its content - that makes it explanatorily prior to [A2]? We are owed an explanation of how Frege could make this priority claim while maintaining [Abstraction Synonymy]. ${ }^{15}$

So what other evidence is there in Grundlagen to support [Abstraction Synonymy]? First, there are similar sounding passages. So, for example, he writes in $\S 62:{ }^{16}$

"In our case, we have to explain (erklären) the sense of the proposition

'the cardinal number which belongs to the concept $\mathrm{F}$ is the same cardinal number which belongs to the concept $\mathrm{G}^{\prime}$;

i.e. we have to express the content of that sentence in a different way, without using the expression

the cardinal number, which belongs to the concept F'."

abstraction principle plays a fundamental role in the Neo-Fregean approach and is further discussed in (Ebert, 2016).

${ }^{13}$ Frege later writes in Grundlagen that "Fruitful determinations of concepts draw borderlines that were not yet given before" $§ 88$. A very similar remark already appears in his "Booles rechnende Logik und die Begriffsschrift" from 1880/81. See (Frege, 1983), p.39.

${ }^{14}$ Landini is the most notable exception here. He offers independent reasons to reject [Abstraction Synonymy] and [BLV Synonymy] as suitable interpretations of Frege's work in (Landini, 1996) and more recently in his monograph (Landini, 2012).

${ }^{15}$ Compare here Dummett who writes: "Frege eventually decided that A2 cannot actually serve to define A1, [...]; this by itself should have warned [Frege] that there was something amiss in holding them to have the same content". (Dummett, 1989), p.7. Alternatively, there is something amiss in ascribing to Frege [Abstraction Synonymy]. See also (Mancosu, 2015) who discusses the history of the second part of the quote at length and identifies the "teachers" that have reversed the true order of things.

${ }^{16}$ Similarly, see his conclusions in $§ 106$. 
(Frege, 1884), p.73.

Granted, it is again very tempting to interpret Frege as endorsing the view that the different expressions capture exactly the same content, even though this is not explicitly said. ${ }^{17}$ After all, he does not say "we have to express the same content in a different way" - a phrase Frege did use before in $\S 8$ of Begriffsschrift as the mark of a content-equality (Inhaltsgleichheit). What seems to be required here, rather, is that the new expression suffices as a general characteristic mark for the equality of numbers; that is not yet to say, however, that such mark is to have the very same content. At least this is not an explicit requirement.

Contrast this with $\S 9$ of Begriffsschrift, published in 1879, where he presents a (superficially) similar model for recognising new entities - in this case: functions - by extracting them from the content of an already understood proposition. Here, Frege allows for different ways of decomposing a proposition by which we arrive at a function, and in doing so he is very explicit that this kind of decomposition does not change the content of the proposition. He writes: "This distinction [between function and argument] does not affect the conceptual content...." (Frege, 1879), §9, p.15 and similarly on p.17. ${ }^{18}$ In contrast, the above passages from Grundlagen are not explicitly claiming that the contents of [A1] and [A2] are the same. While some might interpret this lack of explicitness as a kind of Fregean sloppiness, I take it to be a sign that Frege did not commit himself to [Abstraction Synonymy] with respect to the notion of content in these passages.

Finally, the strongest evidence for [Abstraction Synonymy] can be found in $\S 65$, where he summarises the results of the procedure of splitting up content and writes:

"the line a is parallel to line b" is gleichbedeutend with "the direction of line a is identical to the direction of line b."

$$
\text { (Frege, 1884), p.75. }
$$

Now, Frege could have said that the two statements have "the same content" or express a "content-equality", or even use the phrase "co-contentual" ("in-

\footnotetext{
${ }^{17}$ Austin's translation uses "define" for both "erklären" and "definieren". Since, definiens and definiendum suggests that they are sense identical, yet explanans and explanandum need not be, I prefer to use "explain" rather than Austin's "define" as a translation of "erklären". See also (Rossberg, 2015b) who develops a more precise interpretative basis for this distinction in Frege's Grundgesetze.

${ }^{18}$ Dummett argues that Frege arrives at [Abstraction Synonymy] by "false analogy" to the model of analysis offered in $\S 9$ of Begriffsschrift, compare (Dummett, 1989), p.5. If my suggestion is correct, Dummett overstretches the presumed analogy since the model of $\S 64$ is not intended to be content-preserving.
} 
haltsgleich") but he refrains from saying that. According to Frege, the effect of splitting up a specific content into a new one is that the two propositions are gleichbedeutend. Now, this is not a mere one-off occurrence of the use of gleichbedeutend. Throughout Grundlagen, Frege uses the word "content" usually with respect to specific propositions. He does not, however, use a relational phrase such as " $A$ has the same content as $B$ " (or cognates such as co-contentual). One natural reading of Frege's choice of words is that he simply intends to use " $[\mathrm{A}]$ is gleichbedeutend mit [B]" to mean - excuse the pun - that $[\mathrm{A}]$ and $[\mathrm{B}]$ have the same content. It is very tempting to do so, however let me explore an alternative reading where these two notions are kept distinct.

Firstly, Frege uses the notion gleichbedeutend with respect to propositions for which it isn't immediately obvious that they also express the same content. So, for example, Frege writes in $\S 81$ :

The proposition

"if every object, to which $\mathrm{x}$ stands in the relation $\phi$, falls under the concept $\mathrm{F}$, and if from $\mathrm{d}$ falling under the concept $\mathrm{F}$, whatever $\mathrm{d}$ is, it follows that every object, to which $\mathrm{d}$ stands in the relation $\phi$ falls under the concept $\mathrm{F}$, then $\mathrm{y}$ falls under the concept $\mathrm{F}$, whatever concept F may be."

is to be gleichbedeutend with

"y follows $\mathrm{x}$ in the $\phi$ series"

and with

"x precedes y in the $\phi$-series."

(Frege, 1884), p.94.

Most interpreters would treat this passage as akin to a definition, i.e. Frege would here be interpreted as suggesting that the former statement has the same content as the latter. Yet, if we took seriously the idea that propositions can be gleichbedeutend without necessarily being co-contentual then we arrive at a possibly more charitable interpretation of this and other passages in Frege. $^{19}$

\footnotetext{
${ }^{19}$ Indeed it would help to resolve another Fregean conflict discussed at length by Dummett and more recently by Blanchette: If Frege held a fine-grained cognitive criterion of thought/content-individuation according to which "two sentences express the same
} 
Secondly, even though most interpreters treat Frege's use of Bedeutung in Grundlagen as synonymous with Sinn ("sense") or Inhalt ("content") ${ }^{20}$, it is not clear at all that Frege actually uses them interchangeably. So, for instance, in the context of a discussion of infinite numbers, in particular the cardinal number which belongs to the concept "finite natural number" $\left(\infty_{1}\right)$, he writes in $\S 84$ :

"According to our explanations, this is a completely clear and unambiguous Sinn; and that suffices to justify the usage of the sign $\infty_{1}$ and to secure a Bedeutung for it."

(Frege, 1884), p.97.

Here it is an explanation that fixes the sense of an expression which in turn secures a Bedeutung for that sign. Frege seems to think that the sense of an expression is something distinct from its Bedeutung, and the former plays a role in securing the latter. In fact, Bedeutung has, in this passage, a distinct "referential" feel, which is anticipatory of his famous distinction. A similar usage of bedeuten can be found in Frege's opening sentence of Grundlagen:

"If we raise the question what the number one is, or what the sign

1 bedeute, one will most often receive the answer: well, a thing".

(Frege, 1884), p.I.

Lastly, Frege writes in Grundgesetze (p.X) that his earlier notion of content is now split up into what he now calls thought and truth-value, and so the thought of a proposition is its sense (Sinn), and the truth-value of the proposition is its reference (Bedeutung). Drawing that distinction in this way does not imply that he previously treated Bedeutung to be synonymous with content (or sense for that matter). Admittedly, in his well-known letter to Husser $^{21}$, Frege notes that he had not explicitly drawn the sense-reference distinction in Grundlagen. Still, revisiting his previous use of these terms in Grundlagen, he suggests to replace "Sinn" with "Bedeutung" in $\S \S 97$, 100-102. Interestingly, he does not suggest revisions to $\S \S 62-64$ nor does he suggest any revisions to his previous usage of Bedeutung. To be clear, I'm not claiming that Frege made his famous distinction in Grundlagen. ${ }^{22}$ Rather,

thought only if they are, roughly, fairly-readily recognizable synonyms" (Blanchette, 2012), p.80, various equivalences might not turn out to express the same thought or have the same content even though Frege claims them to be gleichbedeutend.

${ }^{20}$ An exception here is (Weiner, 2007), p.678f.

${ }^{21}$ Letter to Husserl, dated 24.5.1891, published in (Frege, 1976), XIX/1, p.96.

${ }^{22}$ Compare here (Sundholm, 2001). He argues that a draft of Frege's famous article Sinn und Bedeutung was written by May 1890; however, he speculates that Frege might 
I'm questioning whether a charitable interpretation of Frege's Grundlagen should read him as treating the terms Inhalt ("content"), Sinn ("sense"), and Bedeutung (and their respective cognates) as synonymous, simply because he had not yet explicitly drawn his famous distinction.

By way of clarifying my interpretation, let me briefly draw on Dummett's highly insightful discussion of $\S 64 .{ }^{23}$ Dummett is initially hesitant in ascribing [Abstraction Synonymy] to Frege on the basis of this passage. He writes:

"This way of characterising the transition appears to commit Frege to holding that the judgeable content of the two sentences [...] coincides."

(Dummett, 1991c), p.168, (my italics).

Still, he then argues that in Grundlagen Frege did adopt this thesis. ${ }^{24}$ Having ascribed to Frege [Abstraction Synonymy], Dummett shows that adopting it faces numerous problems. However, he offers a distinction - one he claims Frege failed to draw-between a fine-grained notion of sense and a coursegrained notion of content. By means of such a distinction, Dummett argues, Frege could have kept [Abstraction Synonymy] for content, while also claiming that the sense of [A1] and [A2] differ. The reason why I here allude to Dummett's discussion will now be clear. Assuming that Frege did not adopt [Abstraction Synonymy] in the first place, as I argued above, Dummett's search for a distinction in Grundlagen has the wrong starting point: Frege does not require a more fine-grained notion of content, he already has one! Instead what Frege requires is a more coarse-grained alternative; something that [A1] and [A2] share by means of "splitting up content", if they are not sharing the same content.

The suggestion that I'm putting forth is that we should interpret Frege as gesturing towards a distinction of this kind as early as Grundlagen. More specifically, Frege regards [A1] and [A2] to be gleichbedeutend, yet he does not regard them to have the same content. Crucially, at that time, Frege did not yet have an adequate account of what it is for two propositions to be gleichbedeutend. It is only after he came to regard propositions as names

have been influenced by a paper by Moritz Pasch which was published in 1882; it is unclear, though, whether Frege read that article before 1894. I think there is good evidence in Grundlagen that Frege did not treat the expressions "Sinn" and "Bedeutung" interchangeably.

${ }^{23}$ (Dummett, 1991c), chapter 14, in particular, p.168-76.

${ }^{24}$ Admittedly, Dummett's attitude changes in the course of eight pages. He later writes "the synonymy thesis which [Frege] had so vividly expressed [...]" (Dummett, 1991c), p.176. (Dummett's label "the synonymy thesis" is the same thesis that I capture by using [Abstraction Synonymy].) This attitude is again expressed in (Dummett, 1991a), pp.332ff. 
of truths-values and, in turn, truth-values as objects, that he can properly state what it is for two propositions to be gleichbedeutend. ${ }^{25}$

So, to summarise, I have raised doubts about the standard view according to which Frege adopted [Abstraction Synonymy] in Grundlagen. This view is not explicitly endorsed by Frege and it does require treating "content", "sense", and "Bedeutung" as synonyms even though there are passages that suggest otherwise. As such, I hope to have challenged the view that the default position is, once we move to Frege's mature period, that he endorsed [Abstraction Synonymy] and with it the more specific [BLV Synonymy] once he adopted BLV. Of course, more will have to be done properly to develop various repercussions of this interpretation of Grundlagen. Here is not the place to pursue this and so I will turn to Frege's mature period and investigate whether there is better support for [Abstraction Synonymy] or [BLV Synonymy].

\section{BLV Synonymy: From Function und Be- griff to Grundgesetze}

The most compelling evidence in support of [BLV Synonymy] can be found in "Function und Begriff". Having just introduced the sense-reference distinction, Frege writes:

"... so that we have in

$\varepsilon^{2}\left(\varepsilon^{2}-4 \varepsilon\right)=\dot{\alpha}(\alpha \cdot(\alpha-4))$

the expression, that the first value-range is the same as the second. $[\ldots]$

$x^{2}-4 x=x(x-4)$

expresses, if it is understood as [explained] above, though [zwar] the same sense, but in a different way".

(Frege, 1891), p.10-11.

This passage is, no doubt, the clearest indication of a commitment to [BLV Synonymy]. Even though the claim is not made with respect to BLV but a

\footnotetext{
${ }^{25}$ In fact, I think, that Grundlagen is best understood as a mere informal introduction to Frege's logicism which is lacking in detail and is in various ways "unfinished". Hence, that he made use of a distinction for which he did not yet have a detailed account might not be too surprising in this wider context.
} 
specific instance of it, it is natural to generalise Frege's view to apply to the general law. ${ }^{26}$ Interestingly, in his "Ausführung über Sinn und Bedeutung", a manuscript written around 1892-95, so just after "Function und Begriff", Frege does not reiterate that claim. Instead, he writes with respect to a very similar case that we here have

"essentially [im wesentlichen] the same thought".

(Frege, 1983), p.132.

This seems to indicate an important change in Frege's attitude. Frege appears somewhat hesitant and he stops short of asserting that the two sides express the same sense or thought. According to Frege, we have overlap (or strong similarity) of sense or thought between the two expressions, but the use of " $\mathrm{im}$ wesentlichen" (essentially) carries the implicature that he is not committing himself to the thought-identity claim. Some interpreters have suggested that Frege's endorsement of [BLV Synonymy] in the earlier "Function und Begriff" was a slip and that we should not read too much into it since Frege only just introduced the sense-reference distinction. ${ }^{27}$ I think that Frege was likely initially tempted by [BLV Synonymy], yet he gave it up soon thereafter, opting instead for the view expressed above: that the thoughts overlap but they are not identical. ${ }^{28}$

While "Function und Begriff" is a published lecture that Frege gave in Jena and "Ausführung über Sinn und Bedeutung" is part of a manuscript that was not published during his lifetime, it will be instructive to look at

\footnotetext{
${ }^{26}$ I pass over a further complication here. The original concept-script expression of basic law V is a "Roman marker" as it contains Roman letters and as such does not express a thought. Strictly speaking, therefore, it is not really coherent to claim that the two sides of basic law $\mathrm{V}$ express the same sense. Rather, the claim made by proponents of [BLV Synonymy] should be that for any instance of basic law $\mathrm{V}$, the constituent clauses flanking the main identity express the same sense. Alternatively, we could characterise the view more precisely as one which interprets the main clauses of basic law $\mathrm{V}$ as each containing a second-level relational expressions (roughly: $f$ and $g$ have the same value-range, and: $f$ and $g$ always have the same value for the same argument) and so [BLV Synonymy] amounts to the claim that those second-level relational expressions have the same sense. In what follows, I will ignore this complication. (Many thanks to Richard Heck for discussion on this point).

In the above quotation, ' $\mathrm{x}$ ' is a Roman letter, and even though numerous scholars quote this passage adding a quantifier to the second formula it is not present (nor should it be present) in the original.

${ }^{27}$ See for example (Klement, 2002), p.87, and (Dummett, 1981), p.532.

${ }^{28}$ We should not be surprised that Frege never officially acknowledged this change. As Dummett once wrote: "That Frege never publicly acknowledged that he had been wrong [...] is no proof that he did not change his mind: he was never very good at confessing past errors." (Dummett, 1991c), p.176.
} 
the views Frege defended in what he took to be his most important work, namely Grundgesetze der Arithmetik - the culmination of an intellectually very productive phase from 1884-93. Here, Frege is very careful to note that the two sides of BLV are co-referential but he never identifies them has having the same sense. So, when in $\S 3$ he introduces the natural language analogue of BLV, having just outlined in $\S 2$ his sense-reference distinction, he writes:

I use the words

" "the function $\Phi(\xi)$ has the same value-range as the function $\Psi(\xi)$ '

always as co-referential (gleichbedeutend) with the words

'the functions $\Phi(\xi)$ and $\Psi(\xi)$ always have the same value for the same argument.'"

(Frege, 1893), p.7.

That Frege opts to use "co-referential" only is striking and we should thus interpret Frege's initial stipulation in $\S 3$ as presenting the right and left hand side of BLV as having the same reference, which, of course, does not by itself imply sameness of sense. This does not only present a striking continuity in Frege's usage of the term (going back as far as Grundlagen), but additional support for this reading can be drawn from $\S 10$. Frege here reminds the reader in a footnote that to put forth two sides of a "permutation" of BLV as co-referential does not imply that they share the same sense. He writes:

"For then ' $\mathrm{X}(\dot{\varepsilon} \Phi(\varepsilon))=\mathrm{X}(\dot{\alpha} \Psi(\alpha))$ ' too is co-referential (gleichbedeutend) with ' $\mathfrak{a}-\Phi(\mathfrak{a})=\Psi(\mathfrak{a})$ '." [footnote]: "Thereby it is not said that the sense is the same."

(Frege, 1893), p.16.

Thus, gleichbedeutend ("being co-referential") in $§ 10$ has to be understood as a cognate of Frege's technical use of Bedeutung and does not by itself imply sameness of sense. Given this reminder and given that Frege introduces the sense-reference distinction in $\S 2$, we have, I believe, conclusive evidence that Frege's initial stipulation in $\S 3$ has be understood in the same way: he only stipulates co-referentiality. Of course, such a stipulation is compatible with [BLV Synonymy], and Frege's reminder in $\S 10$ does not imply that he denies [BLV Synonymy] - after all he does not consider BLV in that passage - but given that all Frege has done in the initial stipulation of $\S 3$ is to stipulate sameness of reference, it does not provide sufficient grounds to regard both 
sides of BLV as having the same sense. That is an additional claim that requires additional support. ${ }^{29}$

One way to gather such support is, for example, to argue that Frege was inconsistent in his usage of gleichbedeutend. This could be argued for on the basis of $\S 27$ of Grundgesetze. Here, Furth decides to translate the occurrence of gleichbedeutend using the more general "is the same in meaning" implying sameness of sense and reference -instead of his usual "denotes the same as" (sameness of reference). He thinks that Frege uses gleichbedeutend in a non-technical sense in what follows: ${ }^{30}$

"By means of a definition we introduce a new name by determining that it is to have the same sense and the same reference as a name composed of already known signs. The new sign thereby becomes co-referential [gleichbedeutend] with the explaining sign; the definition thus immediately turns into a proposition" (Frege, 1893), p.44-45.

Pace Beaney ${ }^{31}$ I do not regard this passage to be an indication that at least sometimes gleichbedeutend is also meant to imply sameness of sense and that Frege oscillates between a technical use and a non-technical use of that term. Also, I do not think that this passage should be treated as a slip. Rather, this passage indicates that what is important to Frege when it comes to definitions is that they effect co-referentiality. It is the co-referentiality of the two sides of a definition that is required for their employability in a proof, it is the co-referentiality that warrants taking a definition as a true identity statement, and thus, it is the co-referentiality that puts us in a position, as Frege continues, "to cite a definition just like a proposition, replacing the definition-stroke by a judgement-stroke." This emphasis on Bedeutung, rather than Sinn, is important to Frege in Grundgesetze and it is echoed in his review of Husserl in 1894 . He writes: ${ }^{32}$

"Here, a discrepancy manifests itself between the psychological logicians and the mathematicians. The former are concerned with

\footnotetext{
${ }^{29}$ Interestingly, (Simons, 1992) treats the footnote to $\S 10$ as evidence that Frege did adopt [BLV Synonymy], yet I'm unclear why he thinks that. Admittedly, Simons thinks the passage merely offers a "hint". (Schirn, 2006), in contrast, argues against Simons and suggests that this passage does not constitute direct evidence for or against [BLV Synonymy].

${ }^{30}$ Compare (Frege, 1964), p.83fn of Furth's translation.

${ }^{31}$ See (Beaney, 2005), p.296, compare also his important (Beaney, 1996) chapter 5.

${ }^{32}$ Compare also (Simons, 1992) who rightly draws attention to the fact that Frege has little concern for the notion of sense in Grundgesetze. Similar passages to the one quoted here can be found in his Ausührungen über Sinn und Bedeutung ("Comments on sense and reference") in (Frege, 1983), p.133ff., which were written around the same time.
} 
the sense of words and with ideas, which they fail to keep apart. The latter is concerned with the subject matter itself, with the reference of words."

(Frege, 1894), p.183.

Another way to support [BLV Synonymy] is to think of the stipulation of BLV as more akin to a definition, which would, according to $\S 27$, guarantee that the two sides express the same sense and have the same reference. However, Frege reminds us in (Frege, 1903), §146, p.147 that the transformation which is embodied by BLV is not a definition since it does not meet the requirements he set out for a definition proper. Also, nowhere in Grundgesetze does Frege suggest that the transformation involved in BLV requires or even implies sameness of sense. Instead, to justify its use, he notes that many logicians and mathematicians have implicitly made use of it, and he claims to merely make its widespread implicit use explicit by stating it as a basic law of logic. ${ }^{33}$

In fact, Frege has a different attitude towards BLV than to his other logical laws in Grundgesetze. In the foreword, he singles it out as the one principle about which a dispute may arise and writes:

"I take it to be purely logical. At any rate, the place is hereby marked where there has to be a decision."

(Frege, 1893), p.VII.

Importantly, Frege does not here acknowledge that a dispute may arise about the truth of BLV but only about its logicality. ${ }^{34}$ This interpretation seems

${ }^{33}$ The passage reads:

When logicians have long spoken of the extension of a concept and mathematicians have spoken of sets, classes, and manifolds, then such a conversion forms the basis of this too; for, one may well take it that what mathematicians call a set, etc., is really nothing but the extension of a concept, even if they are not always clearly aware of this.

We are thus not really doing anything new by means of this conversion; but we do it in full awareness and by appealing to a basic law of logic. And what we do in this way is completely different from the arbitrary, lawless creation of numbers by many mathematicians."

(Frege, 1903), §147, p.148.

It is thus not surprising that Frege writes in the afterword that he is not the only one affected by the inconsistency: "Solatium miseris, socios habuisse malorum. This consolation, if it is one, is on my side also; for everyone who has made use of extensions of concepts, classes, sets in their proofs is in the same position." (Frege, 1903), Afterword, p.253. Frege mentions Dedekind as a "co-mourner" in the footnote to this quotation.

${ }^{34}$ I here follow (Heck, 2005) and (Heck, 2007). Compare also (Milne, 2014). This 
to sit well with how he finishes the foreword where he effectively rules out a discussion about the truth of his basic principles, he writes:

"And I could only acknowledge it as a refutation if someone indeed showed that a better, more enduring building can be erected on different basic convictions, or if someone proved to me that my basic principles lead to manifestly false conclusions. But no one will succeed in doing so."

(Frege, 1893), p.XXVI.

Nonetheless, he grants that it is not easily recognised as a logical truth because, as he later says in the afterword to Grundgesetze, it always lacked the kind of obviousness that is to be required of a logical law. ${ }^{35}$

A natural way to explain this lack of obviousness is that Frege did not think that the sense on either side of BLV is exactly the same. Indeed, Frege writes in a letter to Russell:

"Everywhere where the coinciding of reference is not self-evident, we have a distinctness of sense."

(Frege, 1976), XXXVI/14, pp.234-5.

So, if Frege did regard the constituent clauses of BLV as expressing the same sense, he should have also held the two sides of BLV as self-evidently coreferential and, as a result, BLV as self-evident. Evidently, he did not and given BLV lacks a feature often associated with a logical principle, Frege admits that doubts may be raised about its logicality. However, as reflected in the above quotation, despite lacking this feature Frege still regarded BLV to be purely logical and to be true. All this suggests that Frege did not adopt [BLV Synonymy].

interpretation is, no doubt, controversial and faces its own challenges which I cannot discuss here in full. For example, one may wonder whether to doubt the logical status of BLV is, ipso facto, to doubt the logical status of value-ranges per se - a doubt that Frege never seems to have entertained. For what it is worth, I think that the kinds of doubts Frege seems to allow concern primarily the grounds for regarding BLV as logical, i.e. whether the grounds are purely logical or whether they involve implicitly an appeal to intuition for example. As such, no corresponding doubt about the logical status of the objects picked out by BLV is thereby suggested. Thanks to an anonymous referee for pressing me on this issue.

${ }^{35} \mathrm{He}$ repeats this attitude in "Über Schoenflies: Die logischen Paradoxien der Mengenlehre" in (Frege, 1983), p.198. He here acknowledges that even before the discovery legitimate doubts about basic law $\mathrm{V}$ could be maintained. But, as I read Frege, these doubts are about its logical status not its truth. 
Now, maybe the hesitation that Frege exhibits towards BLV should be interpreted differently: that Frege is still seeing the relevant senses as if "through a mist", that he took himself not yet to have lifted the "mist" that blurs a proper acknowledgement of the senses and that, ultimately, he was hoping that he would come to regard BLV as expressing the same sense. ${ }^{36}$ If that were so and Frege was not sure which exact sense either side of BLV expresses at the time of Grundgesetze, then surely he would not also entertain [BLV Synonymy].

Finally, let me briefly mention two more general reasons to interpret Frege as not adopting [BLV Synonymy]. The first is made by Dummett: ${ }^{37}$ [BLV Synonymy] is not easily reconciled with the compositionality thesis endorsed by Frege in Grundgesetze. He writes in $\S 32$ of Grundgesetze:

"Now, the simple or complex names of which the name of a truthvalue consists contribute to expressing the thought, and this contribution of the individual name is its sense. If a name is part of the name of a truth-value, then the sense of the former name is part of the thought expressed by the latter."

(Frege, 1893), p.51.

Here "name of a truth-value" is a proposition ("Satz") and "name" (simpliciter) can be any kind of referential expression (such as a predicate). Hence, we here have the "building-block" conception of compositionality, where senses of subsentential expressions are, quite literally, parts of the thought expressed. Given that the right- and left-hand side of BLV involve different concepts that, in turn, have different senses, the two sides cannot express the same thought. Hence, at least in Grundgesetze, Frege could not be committed to both [BLV Synonymy] and this conception of compositionality. $^{38}$

\footnotetext{
${ }^{36}$ This passage is inspired by Künne's extremely insightful discussion in (Künne, 2009), p.673-674. He suggest that Frege's hesitation about BLV might be explained in the way suggested above, but he does not make the additional claim that a proper acknowledgement will lead to [BLV Synonymy]. The metaphors used above appear in his "Logik in der Mathematik" (1914) in (Frege, 1983) and play an important role in (Burge, 1984; Burge, 1990), (Jeshion, 2001), and (Nelson, 2008). However, compare here my footnote 8.

${ }^{37}$ See, in particular (Dummett, 1991c), p.176, (Dummett, 1989). (Landini, 1996), (Klement, 2002) and (Heck and May, 2011) develop interpretations of Fregean senses on which [BLV Synonymy] is false. See (Klement, 2016) for an overview of different interpretation of Fregean senses.

${ }^{38}$ With respect to compositionality in Frege, see e.g. (Heck and May, 2011) and (Künne, 2009), p.654ff. Künne argues that the Grundgesetze conception of compositionality clashes with other theses that Frege held around the time of Grundgesetze and draws attention to weaker readings of compositionality offered in Frege's other writings.
} 
Secondly, we can support the view that Frege did not adopt [BLV Synonymy] from the surprising absence of any appeal to [BLV Synonymy] in Grundgesetze. Not only, as mentioned earlier, does Frege never explicitly endorse [BLV Synonymy], he also never draws on it as an assumption in his arguments or when he offers more or less suggestive considerations in favour of accepting BLV. Granted, Frege provides little positive justification for BLV - be it either for its truth or its logicality - and emphasises instead pragmatic considerations in favour of its acceptance. ${ }^{39}$ For sure, drawing on the presumed synonymy of the two sides of BLV would not have convinced a sceptic, but it would have offered some positive support for why it has to be a logical law or indeed why it has to be true. Strikingly, he never makes this move, which in turn suggests that Frege did not endorse [BLV Synonymy] in Grundgesetze. ${ }^{40}$

So to summarise: in contrast to most interpreters, I believe Frege was not committed to [Abstraction Synonymy] about content during the middle period. Hence, there is no prima facie reason to interpret Frege as endorsing [Abstraction Synonymy] regarding sense or the more specific [BLV Synonymy] in his mature period. Quite the opposite, given that it is doubtful that Frege did entertain [Abstraction Synonymy], there is a prima facie reason not to interpret him as accepting [BLV Synonymy] and, as I tried to show, there are strong independent grounds to interpret Frege as rejecting [BLV Synonymy] from 1893 onwards.

\section{The Incompatible Triad: Logical Truth and Analysis}

Having argued that Frege did not adopt [BLV Synonymy] during his mature period and having offered some reasons to be doubtful that he actually entertained [Abstraction Synonymy], let me highlight a number of issues that arise from this interpretation.

First, does the rejection of [BLV Synonymy] provide a lead out of the incompatible triad? What is obvious is that if Frege did reject [BLV Synonymy], he could not also adopt [Logical Identity]. After all, one of his basic

\footnotetext{
${ }^{39}$ Compare fn 33 above.

${ }^{40}$ Interestingly, Frege never mentions the more general [Abstraction Synonymy] in Grundgesetze either. Indeed, as observed by (May and Wehmeier, 2016), Frege does not even consider Hume's Principle as an abstraction principle in Grundgesetze, but he only discusses either its right to left or its left to right side in isolation. Hence, the more general issue about [Abstraction Synonymy] does not really arise in his mature period. This again seems to fit well with a rejection of [BLV Synonymy] and of [Abstraction Synonymy].
} 
laws of logic does not fit this characterisation. As a result, we may resolve the incompatible triad by rejecting [Logical Identity]: there are logical identity statements that are true and logical, yet do not express the same sense on either side of the main identity sign. Hence, it seems, there is now no barrier to accounting for informativeness by appeal to distinct senses, even if, given [Analysis], it is at bottom a logical one.

Now, one possible doubt may remain: on the interpretation that I have offered, Frege regards BLV as more or less a "special case" about which a debate of its logicality might reasonably arise. Hence, or so a challenge could go, it might still be that in the case of logical identities that are (indisputably) logical, sense identity of the constituent clauses has to hold. Thus, the objection may go, I have not yet fully ruled out the possibility that there are some informative arithmetical identities that once reduced to a logical identity, are such that they are sense identical. Granted, there is such logical space, but it is very hard to motivate such a view, let alone provide reasons for thinking that Frege himself might have adopted it. After all, given that Frege accepts that a basic logical law which takes the form of an identity does not have identical senses, why would he require of non-basic logical identities that their constituent clauses have identical senses? ${ }^{41}$ Hence, I seriously doubt there is a way to resurrect a version of the incompatible triad having rejected [Logical Truth]. ${ }^{42}$ In what follows, I will highlight a striking consequence of rejecting [BLV Synonymy] for our understanding of [Analysis].

Namely, if Frege did not adopt [BLV Synonymy], then given certain assumption about how Frege intends to translate an arithmetical statement into a logical one, he also has to reject [Analysis]. To see this, consider Blanchette's detailed - and to my mind correct - account of how Frege's intended analysis is meant to transform an arithmetical truth into a logical truth. ${ }^{43}$ She convincingly shows how Frege's intended analysis involves an appeal to (a version of) basic law $\mathrm{V}$. That is, in order to arrive at a logical identity (analysans) which is meant to capture the very thought expressed

\footnotetext{
${ }^{41}$ Compare here also (Landini, 1996) who offers numerous convincing examples of logical identities that are not synonymous. Indeed, as one referee pointed out, one may raise doubts about a potential synonymy claim with respect to another basic law, namely basic law VI:

$$
\vdash a=\backslash \vec{\varepsilon}(a=\varepsilon)
$$

Similar considerations as in the case of law $\mathrm{V}$ could be be used to show that the two sides of basic law VI are not sense identical, however, I will postpone discussion of basic law VI to another occasion.

${ }^{42}$ And, of course, there might be other independent reasons to reject [Logical Truth] and to rule out this possible rejoinder.

${ }^{43}$ Compare the excellent (Blanchette, 2012), in particular pp.92ff. See also (Rossberg, 2015a) for a more detailed discussion of Blanchette's interpretation of Frege's analysis.
} 
by an arithmetical identity (analysandum), we require a transition from the right-hand side of BLV to its left-hand side.

However, if Frege did not adopt [BLV Synonymy] and so the two sides of BLV express distinct senses, the result of an analysis which draws on BLV in this way cannot be such that the analysans and analysandum express the exact same thought. Moreover, given compositionality the difference in thought expressed has to be rooted in a difference in sense of one of the subsentential expressions. As a result, a rejection of [BLV Synonymy] also brings about a rejection of the possibility of providing a term by term sensepreserving analysis, i.e. [Analysis]. ${ }^{44}$

If this is correct, the above mentioned possibility of attempting to resurrect a revised version of the incompatible triad seems even less worrying. In effect, on my interpretation, we will have to reject two of the three assumptions that make up the incompatible triad. What these observations nicely show is just how important it is to get clear on Frege's own views about basic law $\mathrm{V}$ in order to understand the main tenets of his wider logicist programme.

However, this discussion gives rise to a no doubt far-reaching issue, which is even more pressing now: ${ }^{45}$ if Frege did not entertain [BLV Synonymy] on what basis did Frege accept BLV? By arguing against [BLV Synonymy] to resolve the incompatible triad, I have ruled out a fairly straightforward, albeit defeasible, explanation of the justified acceptance of this basic law. Assuming that Frege regarded the two sides of BLV to be expressing different senses, we require an alternative account of what makes this logical law acceptable which is compatible with Frege's conception of a basic logical law more generally. Thus offering a way out of the incompatible triad by rejecting [BLV Synonymy] can only ever be half of the story. The other half will be to provide an alternative account of how Frege came to think of BLV as a basic law of logic. ${ }^{46}$ However, this part of the story will have to be told on another occasion. ${ }^{47}$

\footnotetext{
${ }^{44}$ This, of course, leaves it open whether Frege aimed for a weaker form of analysis, one for example that merely requires term by term reference preservation. See also (Blanchette, 2012) for a discussion of the various forms an analysis could take and (Beaney, 1996) for a comprehensive discussion of the problem of analysis in Frege. As an aside: this observation raises some possible concerns for Blanchette's own insightful proposal that Frege was aiming for a weaker form of thought preservation of some basic truths, since it seems to require the truth of [BLV Synonymy].

${ }^{45} \mathrm{An}$ issue raised forcefully in (Milne, 1989).

${ }^{46}$ (Pedriali, 2016) offers an excellent overview of different Frege-inspired approaches to the epistemology of basic laws of logic - some of these approaches are compatible with a rejection of [BLV Synonymy].

${ }^{47}$ I would like to thank Roy T. Cook, Richard Heck, Peter Milne, Erich Reck, Marcus Rossberg, Peter Sullivan, and Alexander Yates for commenting on earlier drafts of this
} 


\section{References}

Beaney, M. (1996). Frege: Making Sense. Duckworth, London.

Beaney, M. (2005). Sinn, bedeutung and the paradox of analysis. In Gottlob Frege Critical Assessments of Leading Philosophers, volume IV, chapter 62, pages 288-310. Routledge, London.

Blanchette, P. (2012). Frege's Conception of Logic. Oxford University Press.

Burge, T. (1984). Frege on extensions of concepts, from 1884 to 1903. The Philosophical Review, 93:3-34. Reprinted in (?), pp.273-298.

Burge, T. (1990). Frege on sense and linguistic meaning. In Bell, D. and Cooper, N., editors, The Analytic Tradition, pages 30-60. Oxford: Blackwell. Reprinted in (?), pp.242-269.

Currie, G. (1982). Frege, sense and mathematical knowledge. Australasian Journal of Philosophy, 60:5-19.

Dummett, M. (1981). The Interpretation of Frege's Philosophy. Harvard, Cambridge, MA.

Dummett, M. (1989). More about thoughts. Notre Dame Journal of Formal Logic, 30(1):1-19. reprinted in (Dummett, 1991a), pp.289-314.

Dummett, M. (1991a). Frege and Other Philosophers. Clarendon Press, Oxford.

Dummett, M. (1991b). Frege and the paradox of analysis. In Frege and Other Philosophers, chapter 2, pages 17-52. Oxford University Press, Oxford.

Dummett, M. (1991c). Frege: Philosophy of Mathematics. Duckworth, London.

paper. I'm very grateful for their suggestions and comments which led to significant improvements. Also, I would like to thank the audience at a Frege workshop in Bucharest as part of the ECAP 2014 and its organiser Sorin Costreie, and the audience of a Frege workshop at MCMP in Munich in 2013 and the organisers Roy T. Cook and Erich Reck where earlier versions of this paper were presented. I would also like to thank two anonymous referees for extremely detailed and challenging comments which lead to numerous changes and improvements. Special thanks go to Walter Pedriali with whom I had numerous conversations about the issues raised in this paper and whose comments and criticisms have been invaluable. 
Ebert, P. A. (2016). A framework for implicit definitions and the a priori. In Ebert, P. A. and Rossberg, M., editors, Abstractionism. Oxford University Press.

Frege, G. (1879). Begriffsschrift: Eine der arithmetischen nachgebildete Formelsprache des reinen Denkens. Verlag L. Nebert, Halle a. d. Saale. English translation of the quoted passages were provided by the author.

Frege, G. (1884). Die Grundlagen der Arithmetik. Eine logisch mathematische Untersuchung über den Begriff der Zahl. Wilhelm Koebner, Breslau. English translation of the quoted passages were provided by the author.

Frege, G. (1891). Function und begriff. In Jenaischen Gesellschaft für Medicin und Naturwissenschaft, Jena. Hermann Pohle. Reprinted in (?), pp.125-142. English translation of the quoted passages were provided by the author.

Frege, G. (1893). Grundgesetze der Arithmetik. Begriffsschriftlich abgeleitet. I. Band. Verlag H. Pohle, Jena. English translation in (Frege, 2013).

Frege, G. (1894). Rezension von: E. G. Husserl, Philosophie der Arithmetik. i. Zeitschrift für Philosophie und philosophische Kritik, 103:313332. Reprinted in (?), pp.179-192.

Frege, G. (1903). Grundgesetze der Arithmetik. Begriffsschriftlich abgeleitet. II. Band. Verlag H. Pohle, Jena. English translation in (Frege, 2013).

Frege, G. (1964). The Basic Laws of Arithmetic. University of California Press, Berkeley and Los Angeles. Edited and translated, with an introduction, by Montgomery Furth.

Frege, G. (1976). Wissenschaftlicher Briefwechsel. Edited by Gottfried Gabriel, Hans Hermes, Friedrich Kampbartel, Christian Thiel, Alber Veraart. Felix Meiner Verlag, Hamburg. English translation of the quoted passages were provided by the author.

Frege, G. (1983). Nachgelassene Schriften. $\left({ }^{1} 1969\right) 2^{\text {nd }}$ rev. ed., by Hans Hermes, Friedrich Kambartel, and Friedrich Kaulbach. Meiner, Hamburg. English translation of the quoted passages were provided by the author.

Frege, G. (2013). Basic Laws of Arithmetic. Oxford University Press, Oxford. Edited and translated by Philip A. Ebert and Marcus Rossberg.

Hale, B. and Wright, C. (2001). The Reason's Proper Study: Essays towards a Neo-Fregean Philosophy of Mathematics. Clarendon Press. 
Heck, R. G. (2005). Julius caesar and basic law v. Dialectica, 59:161-78. reprinted in (Heck, 2011), pp.111-126.

Heck, R. G. (2007). Frege and semantics. Grazer Philosophische Studien, 75:27-63. Reprinted in (?), pp.342-378.

Heck, Jr., R. G. (2011). Frege's Theorem. Clarendon Press, Oxford.

Heck, Jr., R. G. (2012). Reading Frege's Grundgesetze. Oxford University Press, Oxford.

Heck, Jr., R. G. and May, R. (2011). The composition of thoughts. Noûs, 45(1):126-66.

Jeshion, R. (2001). Frege's notion of self-evidence. Mind, 110(440):937-976.

Klement, K. C. (2002). Frege and the Logic of Sense and Reference. Routledge, New York and London.

Klement, K. C. (2016). Grundgesetze and the sense/reference distinction. In Ebert, P. A. and Rossberg, M., editors, Essays on Frege's Grundgesetze. Oxford University Press.

Künne, W. (2009). Die Philosophische Logik Gottlob Freges. Ein Kommentar. Klostermann, Frankfurt.

Landini, G. (1996). Decomposition and analysis in Frege's Grundgesetze. History and Philosophy of Logic, 17:121-39. Reprinted in (?), vol.IV, chapter 65, p.351-375.

Landini, G. (2012). Frege's Notations: What They Are and How They Mean. History of Analytic Philosophy. Palgrave Macmillan.

Mancosu, P. (2015). Grundlagen, section 64: Frege's discussion of definitions by abstraction in historical context. History and Philosophy of Logic, 36:62-89.

May, R. and Wehmeier, K. (2016). The proof of hume's principle. In Ebert, P. A. and Rossberg, M., editors, Essays on Frege's Grundgesetze. Oxford University Press.

Milne, P. (1989). Frege, informative identities, and logicism. The British Journal for the Philosophy of Science, 40:155-166.

Milne, P. (2014). Basic Law V in the light of Frege's correspondence. Unpublished manuscript. 
Nelson, M. (2008). Frege and the paradox of analysis. Philosophical Studies, $137: 159-81$.

Pedriali, W. (2016). When logic gives out. Frege on basic logical laws. In Ebert, P. A. and Rossberg, M., editors, Essays on Frege's Grundgesetze. Oxford University Press. forthcoming.

Picardi, E. (1993). A note on Dummett and Frege on sense - identity. European Journal of Philosophy, 1(1):69-80.

Picardi, E. (2012). Construction and abstraction. In Löffladt, G., editor, Mathematik - Logik - Philosophie. Ideen und ihre historischen Wechselwirkungen. Europa Lehrmittel Verlag, Frankfurt am Main.

Rossberg, M. (2015a). Blanchette on frege on analysis and content. Journal for History of Analytical Philosophy. (forthcoming).

Rossberg, M. (2015b). Frege on definition and explanation. unpublished manuscript.

Schirn, M. (2006). Hume's principle and axiom V reconsidered: critical reflections on Frege and his interpreters. Synthese, 148(1):171-227.

Simons, P. (1992). Why is there so little sense in Grundgesetze. Mind, 101:753-766.

Sluga, H. (1986). Semantic content and cognitive sense. In Haaparanta, L. and Hintikka, J., editors, Frege Synthesized: Essays on the Philosophical and Foundational Work of Gottlob Frege, pages 47-64. Reidel.

Sluga, H. D. (1980). Gottlob Frege. Routledge and Kegan Paul, London.

Sullivan, P. M. (2007). How did Frege fall into the contradiction? Ratio, 20(1):91-107.

Sundholm, G. (2001). Frege, August Bebel and the return of alsace-lorraine: the dating of the distinction between Sinn and Bedeutung. History and Philosophy of Logic, 22(2):57-73.

Thiel, C. (1968). Sense and Reference in Frege's Logic. Dordrecht, Reidel.

Weiner, J. (2007). What's in a numeral? Frege's answer. Mind, 116(463):677716 .

Wright, C. (1983). Frege's Conception of Numbers as Objects. Aberdeen University Press, Aberdeen. 